\title{
Correction: Pomalidomide, bortezomib, and low-dose dexamethasone in lenalidomide-refractory and proteasome inhibitor-exposed myeloma
}

\author{
P. G. Richardson ${ }^{1}$ - C. C. Hofmeister ${ }^{2}$ N. S. Raje ${ }^{3}$ D. S. Siegel ${ }^{4}$ - S. Lonial ${ }^{5}$ - J. Laubach ${ }^{1}$ - Y. A. Efebera ${ }^{2}$. \\ D. H. Vesole ${ }^{4}$ - A. K. Nooka ${ }^{5}$ J. Rosenblatt ${ }^{6} \cdot$ D. Doss ${ }^{1} \cdot$ M. H. Zaki ${ }^{7} \cdot$ A. Bensmaine ${ }^{7} \cdot$ J. Herring $^{7} \cdot$ Y. Li $^{7} \cdot$ L. Watkins $^{7}$. \\ M. S. $\mathrm{Chen}^{7} \cdot$ K. C. Anderson ${ }^{1}$
}

Published online: 14 September 2018

(c) The Author(s) 2018. This article is published with open access

Correction to: Leukemia; https://doi.org/10.1038/leu.2017. 173; published online 2 June 2017

Following the publication of this article, the authors noted that the pomalidomide dose for the additional SC cohort in Fig.1 was incorrectly listed. The correct dose for pomalidomide in the additional SC cohort should be the maximum tolerated dose of $4 \mathrm{mg} /$ day, not $2 \mathrm{mg} /$ day as listed in the original Fig. 1. The authors apologize for any inconvenience caused.

P. G. Richardson

paul_richardson@dfci.harvard.edu

1 Jerome Lipper Multiple Myeloma Center, Department of Medical Oncology, Dana-Farber Cancer Institute, Harvard Medical School, Boston, MA, USA

2 Division of Hematology, Department of Internal Medicine, The Ohio State University, Columbus, OH, USA

3 Massachusetts General Hospital, Boston, MA, USA

4 John Theurer Cancer Center, Hackensack University Medical Center, Hackensack, NJ, USA

5 Department of Hematology and Medical Oncology, Winship Cancer Institute, Emory University School of Medicine, Atlanta, GA, USA

6 Beth Israel Deaconess Medical Center, Harvard Medical School, Boston, MA, USA

7 Celgene Corporation, Summit, NJ, USA
Open Access This article is licensed under a Creative Commons Attribution 4.0 International License, which permits use, sharing, adaptation, distribution and reproduction in any medium or format, as long as you give appropriate credit to the original author(s) and the source, provide a link to the Creative Commons license, and indicate if changes were made. The images or other third party material in this article are included in the article's Creative Commons license, unless indicated otherwise in a credit line to the material. If material is not included in the article's Creative Commons license and your intended use is not permitted by statutory regulation or exceeds the permitted use, you will need to obtain permission directly from the copyright holder. To view a copy of this license, visit http://creativecommons. org/licenses/by/4.0/. 